\section{OS FOCOS DA APRENDIZAGEM CIENTÍFICA: EM BUSCA DE EVIDÊNCIAS DA APRENDIZAGEM EM UMA ATIVIDADE LÚDICA}

Scientific learning focuses: in search of learning evidence in a ludic activity

Los focos del aprendizaje científica: la busca por evidencias del aprendizaje en una actividad lúdica

\section{Resumo}

O presente artigo traz os resultados de uma pesquisa que teve por objetivo buscar evidências da aprendizagem científica em uma atividade lúdica, baseada na temática "energia", desenvolvida com estudantes de um curso técnico de nível médio, em uma instituição pública do interior do estado de Goiás. Para tanto, os Focos da Aprendizagem Científica (FAC) e as Fases de Desenvolvimento do Interesse foram concebidos como categorias a priori na tentativa de identificar, nas falas dos sujeitos da pesquisa, evidências dessa aprendizagem. A atividade desenvolvida ocorreu no laboratório de informática da instituição, com a utilização do software de simulações Phet. Foi possível encontrar evidências de algumas dimensões da aprendizagem descritas pelos focos e compreender a evolução do interesse nesse processo. Nesse sentido, verificamos que o instrumento utilizado para a análise dos dados contribui para a busca de uma mensuração da aprendizagem em atividades lúdicas.

Palavras-chave: Interesse; Focos da Aprendizagem Científica; Lúdico;Simulação Phet.

\section{Abstract:}

The article returns the results of a research which aimed at seeking for scientific learning evidence in a ludic activity based on the theme 'energy', developed with students from a high school technical course in a public institution located in an interior city of the state of Goiás. Therefore, Scientific Learning Focuses (SLF - FAC) and Stages of Interest Development have been conceived as a priori categories to identity evidences of this learning in the research subjects' speeches. The activity took place in the computer laboratory at the institution with the use of Phet simulation software. It was possible to encounter evidence of some of the learning dimensions described by the focuses and comprehend the evolution of interest within this process. In this sense, we have verified that the instrument used for data analysis has contributed to the quest for learning measurement in ludic activities.

Keywords: Interest; Scientific Learning Focuses; Ludic; Phet Simulation.

\section{Resumen}

El presente artículo trae los resultados de una investigación que tuvo por objetivo buscar evidencias del aprendizaje científico en una actividad lúdica, basada en la temática "energía", desarrollada con estudiantes de un curso técnico de nivel medio, en una institución pública del interior del estado de Goiás. Para ello, los Focos del Aprendizaje Científico (FAC) y las Fases de Desarrollo del Interés se concibieron como categorías a priori en el intento de identificar, en las conversaciones de los sujetos de la investigación, evidencias de ese aprendizaje. La actividad desarrollada ocurrió en el laboratorio de informática de la institución, con la utilización del software de simulaciones Phet. Es posible encontrar evidencias de algunas dimensiones del aprendizaje descritas por los focos y comprender la evolución del interés en ese proceso. En ese sentido, verificamos que el instrumento utilizado para el análisis de los datos contribuye a la búsqueda de una medición del aprendizaje en actividades lúdicas.

Palabras clave: Interés. Focos del Aprendizaje Científico. Lúdico. Simulación Phet.
AUTORES:

SÉRGIO SILVA FILGUEIRA ${ }^{1}$

ORCID 0000-0002-4104-8196

${ }^{1}$ Instituto Federal de Goiás (IFG)

LUDIMILA MONTEIRO DA SILVA ${ }^{2}$

ORCID 0000-0002-4152-9491

${ }^{2}$ Instituto Federal de Goiás (IFG)

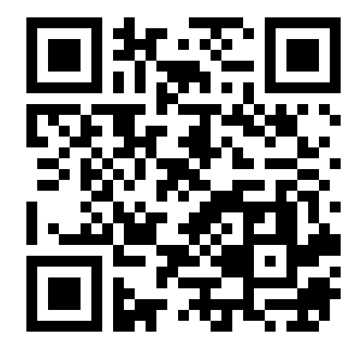

Para citar este artigo:

FILGUEIRA, S. S.; SILVA, L. M. Os focos da aprendizagem científica: Em busca de evidências da aprendizagem em uma atividade lúdica. Revista Eletrônica Ludus Scientiae, Foz do Iguaçu, v. 01, n. 01, p. 16-25, jan./jul. 2017. 


\section{INTRODUÇÃO}

Nas últimas décadas, autores como Soares (2008), Ramos (1990), Rosa (2002), Huizinga (2001) e outros têm realizado pesquisas sobre o uso de atividades lúdicas como estratégias facilitadoras da aprendizagem, a maioria deles tendo como base a teoria piagetiana. Segundo Soares (2004, p. 177),

Acredita-se que o desenvolvimento cognitivo também passa pelo lúdico, podendo ser consequência dele, como defendido por Piaget, ou ainda, parte e causa do mesmo, complemento e contraponto defendido por este trabalho de tese. Notou-se, durante o trabalho, que muitos dos conceitos discutidos se tornaram mais claros, aumentandose o interesse dos alunos pelos mesmos e isso só se tornou possível pela aplicação dessas atividades lúdicas.

As raízes do lúdico estão também em autores como Chateau (1987), que afirma que a criança logo percebe infrutíferas suas tentativas de inserção nesse mundo: seus dedos são muito escorregadios para as louças, seu espírito muito impaciente para a jardinagem, sua força muito limitada para a maioria dos trabalhos masculinos, sua habilidade muito rudimentar para o trabalho feminino.

Segundo Huizinga (2001), desde a mais tenra idade, as representações das crianças mostram um alto grau de imaginação e durante esse processo de personificação, verifica-se uma intensa satisfação em representar e assim, mostrar a execução das possibilidades que lhe foram tolhidas. Ainda, ela se sente tremendamente satisfeita quando há o público adulto para admirá-la.

Os resultados de pesquisas que compartilham esse referencial teórico apontam que, dentre outros aspectos, as atividades lúdicas despertam o interesse dos estudantes para a aprendizagem das ciências. De modo geral, se bem planejadas, essas atividades possibilitam um deslocamento do processo de ensino e aprendizagem para uma perspectiva mediadora, no qual o professor se vê no papel de coordenar as interações entre os estudantes, sendo isso um facilitador da aprendizagem. A discussão que fazemos aqui é no sentido de avançar na compreensão do que seria a aprendizagem e de que modo ela pode ser mensurada. O despertar do interesse nos alunos não pode, por si só, ser uma garantia de que houve aprendizagem. Messeder e Moradillo (2015) destacam que muitos artigos que relatam pesquisas e experiências lúdicas na sala de aula carecem de um referencial teórico que sustente essas práticas.

Garcez (2014, p. 118), em dissertação que versa sobre o estado da arte no lúdico no ensino de Química no Brasil, reforça esse pensamento:

Uma característica observada na maioria dos trabalhos é sua débil relação com a fundamentação teórica sobre o lúdico no ensino de química. Verifica-se que a maioria dos trabalhos apresentam pequenas discussões ou apenas cita o lúdico. Às vezes, estas falas se restringem a uma breve revisão bibliográfica, apresentação das características intrínsecas ao lúdico ou definição de jogo educativo.

Oliveira e Soares (2005, p. 22), em um trabalho sobre Júri Químico, destacam o interesse como uma das principais características das atividades lúdicas:

O interesse não pode ser gerado, pois já existe intrinsecamente; no entanto, pode e deve ser despertado. A realização da atividade lúdica, com todas as suas possibilidades de interação, levou a uma constante busca e criação de alternativas a serem debatidas nos grupos e no júri. Ou seja, assim que o aluno tem contato com a proposta do júri, envolve-se completamente com a atividade, buscando em todas as etapas do processo novas ideias e conceitos, fato que não ocorre em aulas expositivas nas quais são apresentados aos alunos os conceitos e, futuramente, lhes é cobrado um saber pronto e acabado que deve ser assimilado sem a prévia averiguação do interesse ou não pelo assunto por parte dos aprendizes. 
É muito comum a utilização do termo "interesse" em artigos sobre atividades lúdicas. Conforme ressaltamos, o interesse demonstra a criação de um ambiente favorável para a aprendizagem, mas não ela em si. Essa mensuração é algo complexo. No sentido de buscar uma contribuição para esse campo teórico, utilizamos um referencial que pode ser aplicado como um instrumento para identificar as evidências da aprendizagem científica.

No ano de 2009, sob a coordenação do National Research Council (Conselho Nacional de Pesquisa) dos Estados Unidos da América (EUA), foi publicado um relatório bastante amplo sobre a aprendizagem informal, com o título Learning science in informal environments: people, places $e$ pursuits. O objetivo maior desse relatório era examinar as possibilidades para o aprendizado de ciências em situações de aprendizagem em ambientes não formais.

Segundo Arruda et al. (2013):

Ambientes informais incluem uma ampla gama de configurações, como conversas familiares em casa, visitas a museus, centros de ciência ou outros ambientes planejados, além de atividades diárias como jardinagem, atividades recreativas como caminhadas e pesca e participação em clubes. Praticamente todas as pessoas, de todas as idades e formações, se envolvem em atividades que podem apoiar a aprendizagem das ciências no decurso da vida diária. (NATIONAL RESEARCH COUNCIL, 2009, p. 1, tradução nossa).

Os pesquisadores em educação científica informal distinguem três concepções amplas de aprendizado: lifelong learning, que se refere à aquisição de conhecimentos e competências científicas fundamentais ao longo da vida, geralmente associados a algumas necessidades e interesses que podem variar com o tempo; life-wide learning, relativa ao fato de o aprendizado informal ocorrer à medida que as pessoas circulam nas mais variadas situações e ambientes que encontram em sua vida; life-deep learning, associada ao aprendizado de aspectos culturais, a valores morais, éticos, religiosos e sociais, que eventualmente guiam a ação e o juízo das pessoas sobre si mesmas e sobre os outros (NATIONAL RESEARCH COUNCIL, 2009). Nos Estados Unidos, a educação informal é muito valorizada. É considerada um dos três pilares do sistema educacional americano, os outros sendo a Escola Básica e a Educação Superior. Para o Departamento de Educação daquele país, a aprendizagem informal seria necessária para assegurar a competitividade econômica dos EUA, em particular, a capacidade das instituições educacionais de produzirem cidadãos cientificamente alfabetizados e futuros cientistas, engenheiros, matemáticos etc. (NATIONAL RESEARCH COUNCIL, 2009).

O “referencial ecológico" utiliza três “olhares” para examinar os ambientes de aprendizagem: um olhar centrado na pessoa, que foca em fenômenos intrapsicológicos, tais como o desenvolvimento do interesse, as respostas afetivas, a identidade, os conhecimentos prévios, as diferenças entre peritos e novatos e a metacognição; um olhar centrado no lugar, que leva em consideração os lugares onde se dá o aprendizado e as atividades típicas a eles associadas; e um olhar centrado na cultura, que assume, baseado em Vygotsky, que todo aprendizado é um processo cultural (NATIONAL RESEARCH COUNCIL, 2009, p. 34-41).

Ressaltamos que, embora o relatório supracitado apresente ênfase na aprendizagem em ambientes informais e não formais, não temos a pretensão de relegar as atividades lúdicas, objeto de discussão desse manuscrito, a tais espaços, como se esta não fosse possível de ser desenvolvida em ambientes formais. Tal interpretação reforçaria certas visões distorcidas e estereotipadas do lúdico. Acreditamos que o propósito do relatório, através dos Focos da Aprendizagem Científica apresentados abaixo, é possibilitar a busca de uma mensuração da aprendizagem, sendo esta compreendida para além dos espaços formais de educação. 


\section{Focos da Aprendizagem Científica (FAC)}

Segundo Arruda et al. (2013), o aprendizado científico em ambientes informais é concebido, no relatório do National Research Council (2009, p. 42), como fios de uma corda - strands of a rope "tecidos para produzir experiências, ambientes e interações sociais", atraindo "pessoas de todas as idades e experiências na direção de uma maior compreensão, fluência e perícia científicas". Tais autores preferiram denominar tais 'strands' de focos do aprendizado científico informal, o que também fazemos neste artigo.

Um aspecto importante desses focos é que eles estão interligados, de tal forma que o progresso em um deles contribui para o desenvolvimento dos outros (FENICHEL; SCHWEINGRUBER, 2010, p. 2-5). Os seis focos são descritos a seguir:

Quadro 1: Focos da Aprendizagem Científica (FAC).

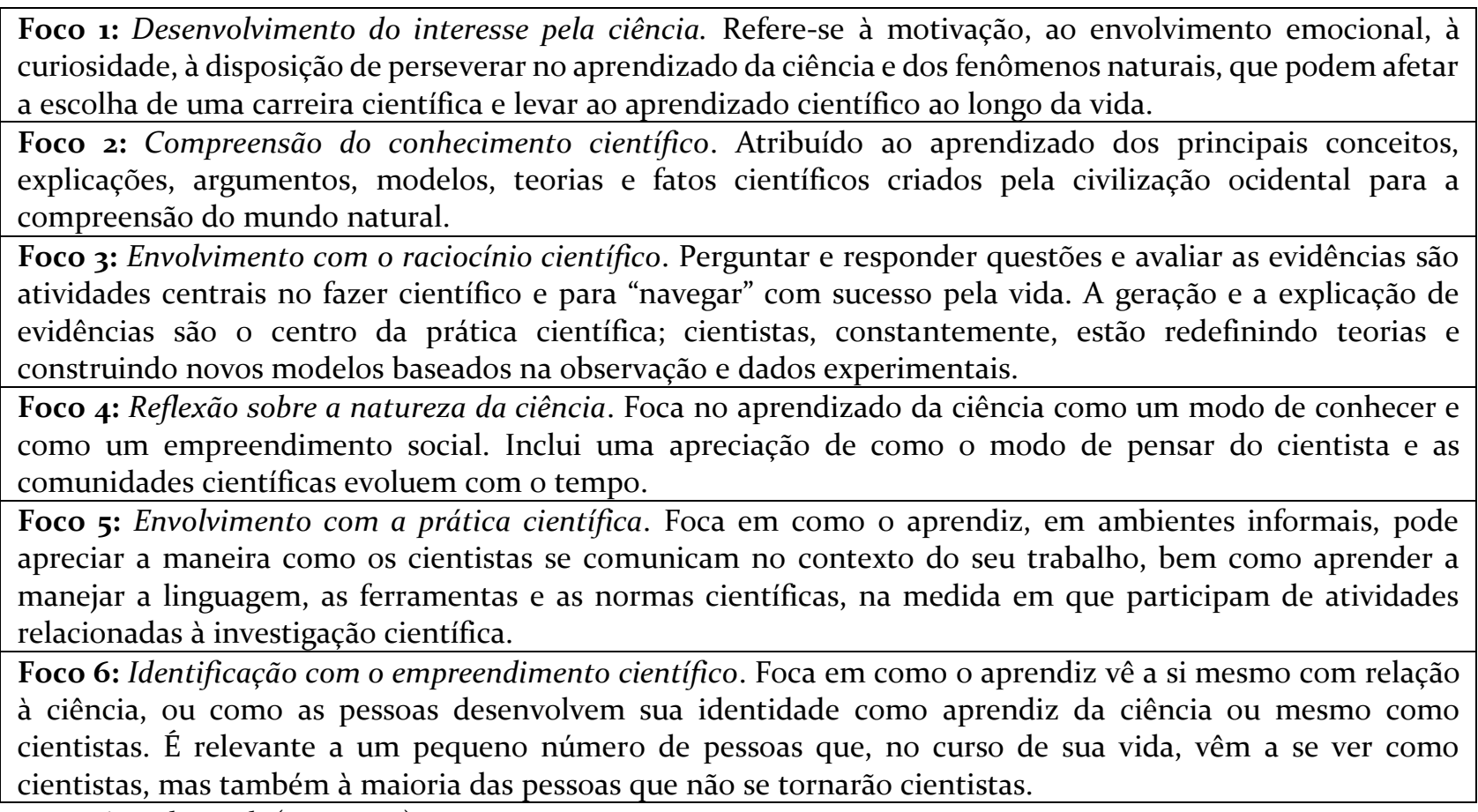

Fonte: Arruda et al. (2013, p. 8).

Embora, nos resultados apresentados neste trabalho, tenham sido identificados mais de um foco, consideramos relevante fazer uma análise mais específica com o primeiro foco (desenvolvimento do interesse pela ciência). Na psicologia cognitiva, Hidi e Renninger (2006) apresentam um modelo teórico de quatro fases do desenvolvimento do interesse (MDI), que consistem em: Interesse Situacional Acionado; Interesse Situacional Mantido; Interesse Individual Emergente; Interesse Individual Bem Desenvolvido.

Segundo os autores, o nível de interesse, os fatores emocionais e os afetivos exercem influência direta na aprendizagem. Os educadores parecem desconsiderar a importância de despertar o interesse nos estudantes, continuando suas práticas em um cenário de grandes dificuldades e desmotivação. $\mathrm{O}$ fato de o docente não reconhecer seu papel no despertar e na manutenção do interesse dos alunos leva a uma constatação simplista: os estudantes têm ou não têm interesse.

De acordo com Martin (2016, p. 25),

O MDI compreende um instrumento de análise de grande potencial para apoiar intervenções educacionais. Ele foi construído por meio de estudos empíricos sobre interesse e aprendizagem. Quando Hidi e Renninger (2006) propõem esse modelo, 
eles se baseiam nas maneiras pelas quais pesquisadores têm mantido o interesse e caracterizam seus estudos ao descreverem as fases relacionadas ao interesse.

É importante destacar que o interesse se difere de outras variáveis motivacionais, pois ele engloba tanto aspectos afetivos como cognitivos. Esses componentes, ainda que separados, agem como sistemas interativos. Hidi e Renninger (2006) colocam que o componente afetivo do interesse é caracterizado por emoções positivas, acompanhadas de envolvimento, ao passo que o componente cognitivo faz referência a atividades de percepção e a atividades relacionadas ao envolvimento.

Cabe ressaltar também que o interesse tem dimensão biológica. Os autores destacam que pesquisas neurocientíficas sobre métodos cerebrais e busca de comportamento indicam que atividades interessadas têm uma base biológica em todos os mamíferos. Aparentemente, há um consenso de que o sistema de busca é um sistema cerebral emocional, evolutivo e geneticamente estabelecido. É uma base biológica do estado psicológico do interesse no sentido de que a pessoa é física, cognitiva ou simbolicamente envolvida com o objeto de seu interesse (HIDI; RENNINGER, 2006).

No Quadro 2, trazemos uma compilação dessas quatro fases do interesse, a fim de elucidar os leitores a respeito de seus critérios.

Quadro 2: Fases do desenvolvimento do interesse.

\begin{tabular}{|c|c|c|c|c|}
\hline & $\begin{array}{l}\text { 1: Interesse } \\
\text { acional } \\
\text { onado }\end{array}$ & $\begin{array}{l}\text { se 2: Interesse } \\
\text { tuacional Mantido }\end{array}$ & $\begin{array}{l}\text { : Interesse } \\
\text { idual } \\
\text { gente }\end{array}$ & ndividual \\
\hline & $\begin{array}{l}\text { Estado psicológico } \\
\text { resultante de } \\
\text { mudanças em } \\
\text { curto prazo em } \\
\text { processos afetivos e } \\
\text { cognitivos. }\end{array}$ & $\begin{array}{l}\text { Estado psicológico que } \\
\text { envolve atenção e } \\
\text { persistência durante } \\
\text { um período extenso, } \\
\text { e/ou recorre e persiste. }\end{array}$ & $\begin{array}{l}\text { Estado psicológico e } \\
\text { início de uma } \\
\text { predisposição } \\
\text { relativamente } \\
\text { duradoura para buscar } \\
\text { novo envolvimento } \\
\text { com tipos particulares } \\
\text { de conteúdo. }\end{array}$ & $\begin{array}{l}\text { Estado psicológico e uma } \\
\text { predisposição relativamente } \\
\text { duradoura para envolver-se } \\
\text { novamente com classes } \\
\text { particulares de conteúdo. }\end{array}$ \\
\hline 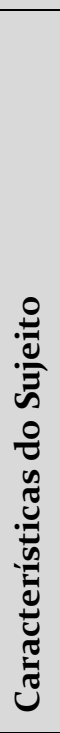 & $\begin{array}{l}- \text { - Atende ao } \\
\text { conteúdo, mesmo } \\
\text { que fugazmente. } \\
\text { - Para se envolver, } \\
\text { precisa de apoio de } \\
\text { outros e ocorrer } \\
\text { por meio de } \\
\text { modelo } \\
\text { instrucional. } \\
\text { - Pode experienciar } \\
\text { sentimentos } \\
\text { positivos ou } \\
\text { negativos. } \\
\text { - Pode estar ou não } \\
\text { ciente do seu } \\
\text { envolvimento. }\end{array}$ & $\begin{array}{l}\text { - Volta a se envolver } \\
\text { com o conteúdo que } \\
\text { anteriormente lhe } \\
\text { acionou atenção. } \\
\text { - É apoiado por outros } \\
\text { para achar conexões } \\
\text { entre suas habilidades, } \\
\text { conhecimentos e } \\
\text { experiência prévia. } \\
\text { - Têm sentimentos } \\
\text { positivos. } \\
\text { - Está desenvolvendo } \\
\text { conhecimento sobre o } \\
\text { conteúdo. } \\
\text { - Está desenvolvendo } \\
\text { uma ideia do valor do } \\
\text { conteúdo. }\end{array}$ & $\begin{array}{l}\text { - É provável que se } \\
\text { envolva outra vez com } \\
\text { o conteúdo, de modo } \\
\text { independente. } \\
\text { - Tem questões de } \\
\text { curiosidade que levam } \\
\text { a buscar respostas. } \\
\text { - Têm sentimentos } \\
\text { positivos. } \\
\text { - Apropriação de } \\
\text { conhecimento e valor } \\
\text { sobre o conteúdo. } \\
\text { - Está bem focado nas } \\
\text { suas próprias } \\
\text { questões. }\end{array}$ & $\begin{array}{l}\text { - Volta a se envolver com o } \\
\text { conteúdo de modo } \\
\text { independente. } \\
\text { - Têm questões de curiosidade. } \\
\text { - Facilmente se autorregula } \\
\text { para reenquadrar questões e } \\
\text { buscar respostas. } \\
\text { - Têm sentimentos positivos } \\
\text { intensificados. } \\
\text { - Pode perseverar entre } \\
\text { frustração e desafios a fim de } \\
\text { alcançar objetivos. } \\
\text { - Reconhece a contribuição de } \\
\text { outros à disciplina. } \\
\text { - Busca feedback ativamente. }\end{array}$ \\
\hline
\end{tabular}

Fonte: Adaptado de Hidi e Renninger (2006).

\section{Percurso metodológico e desenvolvimento de uma atividade lúdica}

De acordo com Gatti (2002), a pesquisa é o ato pelo qual procuramos obter conhecimento sobre alguma coisa. Contudo, no sentido mais estrito, visa a criação de um corpo de conhecimento sobre determinado assunto. A pesquisa que realizamos foi de natureza qualitativa, na qual tomamos os focos 
da aprendizagem científica como categorias a priori, o que nos possibilitou evidenciar indícios da aprendizagem científica. Utilizamos também um referencial da psicologia cognitiva como forma de aprofundar a análise. Cabe ressaltar que cada foco representa uma dimensão da aprendizagem, sendo esta composta de múltiplos aspectos, estando sempre mutuamente relacionados, ou seja, o desenvolvimento de um favorece o despertar de outro.

Sobre pesquisa qualitativa, Flick (2009) salienta que as ideias centrais que a orientam diferem daquelas da pesquisa quantitativa. Os aspectos essenciais da pesquisa qualitativa consistem na escolha adequada de métodos e teorias convenientes; no reconhecimento e na análise de diferentes perspectivas; nas reflexões dos pesquisadores a respeito de suas pesquisas como parte do processo de produção de conhecimento; e na variedade de abordagens e métodos. $\mathrm{O}$ mesmo autor destaca alguns aspectos essenciais da pesquisa qualitativa, entre eles: a apropriabilidade de métodos e teorias; as perspectivas dos participantes e sua diversidade; a reflexividade do pesquisador e da pesquisa; a variedade de abordagens e métodos. Nas palavras de Flick (2009, p. 8) temos:

A pesquisa qualitativa não se baseia em um conceito teórico e metodológico unificado. Diversas abordagens teóricas e seus métodos caracterizam as discussões e a prática da pesquisa. Os pontos de vista subjetivos constituem um primeiro ponto de partida. Uma segunda corrente de pesquisa estuda a elaboração e o curso das interações, enquanto uma terceira busca reconstruir as estruturas do campo social e o significado latente das práticas.

A atividade na qual ocorreu a coleta de dados foi realizada com 17 alunos de um curso técnico de nível médio de uma instituição federal do interior do estado de Goiás. Inicialmente, disponibilizamos aos alunos um material sobre trabalho, energia cinética, energia potencial gravitacional e energia mecânica. Foram explicados os conceitos apresentados no material e, em seguida, utilizamos uma simulação para que os estudantes pudessem compreender melhor tais conceitos.

A simulação foi extraída do site do Phet colorado, em que constam inúmeras simulações, de várias áreas do conhecimento.

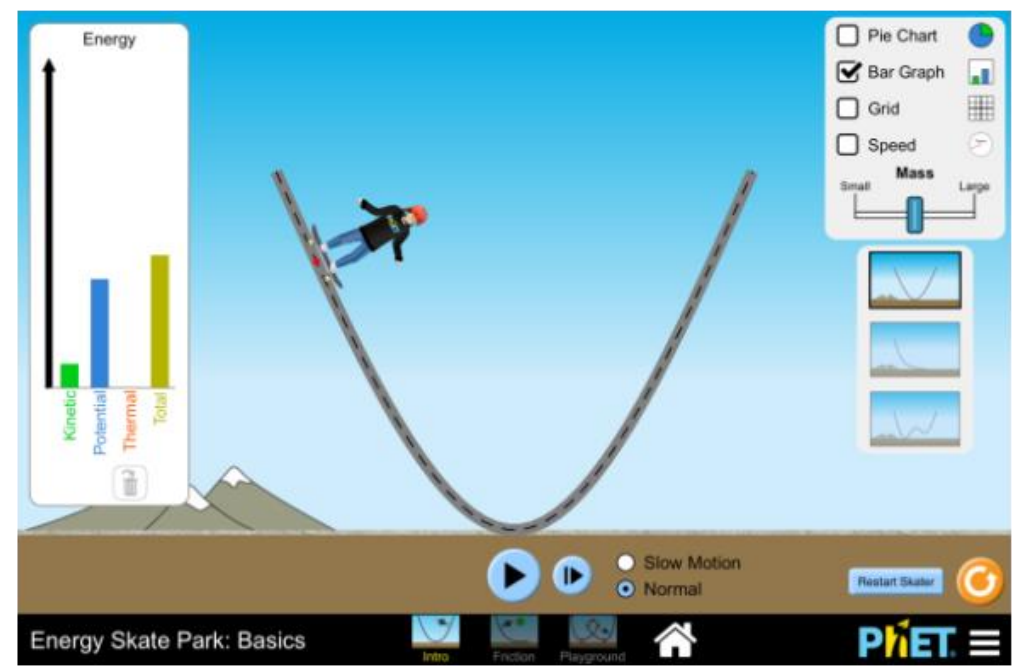

Figura 1: Simulação "Energy skate”.

As simulações estão disponíveis nesse site, para download e também podem ser realizadas on line. O endereço é: https://phet.colorado.edu/pt BR/. 
Para registro da atividade, as aulas eram filmadas e, posteriormente, transcritas. Assim que os alunos chegavam ao laboratório de informática, já brincavam com a simulação disponível no computador. Mesmo antes de se apresentar algum material, eles demonstraram certo interesse para o assunto, pois faziam perguntas a respeito.

O material sobre energia e trabalho foi apresentado e explicado em sala de aula de forma dinâmica e com a participação dos alunos. Logo após, a simulação no software Phet colorado, que encontra-se disponível no site supracitado, foi utilizada.

Assim que a simulação foi apresentada, demos um nome para o skatista, BOB, pelo fato de alguns alunos conhecerem o Bob Burnquist, recordista em esportes radicais, como o skate. A simulação se dividiu em três telas, cada uma com um tipo de pista. Em função do tipo da pista podíamos observar a diferença de energia em cada uma das situações. Durante a realização da atividade, os estudantes foram incentivados a manipular o software, de maneira a observar o que acontecia com os valores das energias cinética e potencial quando $\mathrm{BOB}$ se movimentava na pista. A ideia era colocá-los em uma situação de investigação, na qual eles levantavam hipóteses, que poderiam ser testadas.

Assumimos que o interesse é algo pessoal, inerente a cada ser humano, e que pode se dar de diversas formas, pois determinado assunto, ao ser apresentado a um grupo de pessoas, pode despertar diferentes interesses, assim como nos indica Soares (2004, p. 30):

[...] o interesse não pode ser gerado, mas sim, despertado, pois já existe intrinsecamente, assim como o jogo. O interesse nada mais é do que o resultado de uma carência específica, que gera uma necessidade de aprendizado. No que diz respeito à aprendizagem, o interesse é o resultado de uma carência do conhecimento.

Essa característica evidenciou-se nesta investigação, uma vez que percebemos o interesse dos alunos antes mesmo de as atividades serem realizadas. $O$ interesse foi acionado pela existência de carência desses conhecimentos, explicitada quando fizemos a seguinte pergunta: o que é energia? O Aluno 1 responde, imediatamente: “Energia é o grau de agitação das moléculas.” (Aluno 1) (Foco 2).

Percebemos que a resposta desse aluno está relacionada à ideia de energia térmica. Todavia, a energia envolvida na simulação apresentada pelo simulador é cinética e potencial. Embora o aluno não tenha mostrado um conceito amplo de energia, seu conhecimento prévio lhe permitiu externar um recorte desse conceito. Dando sequência à apresentação de alguns exemplos capturados durante a coleta de dados, trazemos a continuidade desse diálogo deflagrado pela pergunta: o que é energia?

Ok, isso que você diz está relacionado com energia térmica. Mas, e no caso dessa simulação da pista de skate, quais as energias envolvidas? Observem o que acontece quando Bob está no ponto mais alto da pista, como fica a energia? (Docente).

Quando o BOB está no topo da pista a energia potencial vai lá em cima? (Aluno 2) (Foco 3).

É por causa da energia acumulada. (Aluno 1) (Foco 2).

Quanto mais eu levo ele (o BOB) pra cima, mais o trem aumenta. (Aluno 2) (Foco 3).

Como podemos caracterizar a energia potencial então? (Docente).

Essa energia tem a ver com a altura. Ele sobe, a energia aumenta, ele desce a energia diminui. (Aluno 2) (Foco 2). 
Mas quando ele desce, outra energia aumenta aqui, a energia cinética. A energia cinética tem a ver com a velocidade então, pois quando ele desce, fica mais rápido. (Aluno 1) (Foco 2).

Nesse episódio interativo-discursivo, é possível perceber evidências dos Focos 2 e 3. O Foco 2 (Compreensão do conhecimento científico) é percebido quando os alunos, a partir da mediação e da percepção do que ocorre com a energia quando Bob movimenta-se na pista, apresentam uma resposta dentro do que é esperado para tais conceitos. O Foco 3 (Envolvimento com o raciocínio científico) torna-se explícito quando alguns alunos fazem perguntas e outros respondem, buscando evidências para suas hipóteses através da simulação.

No diálogo a seguir, percebemos também evidências do Foco 3, a partir da pergunta:

Alguém sabe me dizer como ficam as energias no ponto mais alto da rampa? (Docente).

Energia potencial está no máximo e a energia cinética no mínimo. (Aluno 17) (Foco 3).

Hum, aqui é bom que dá pra testar as energias nesse "jogo". Quando ele desce, a energia cinética aumenta e a potencial diminui. (Aluno 5) (Foco 3).

Brougère (1998) defende que o interesse leva à motivação. Quando se desperta a curiosidade e o interesse no ser humano, estamos motivando-o a buscar conhecimento e facilitando o processo de aprendizagem. O autor indica, ainda, que uma das contribuições do jogo à educação é o fato de permitir ao aluno ser mais eficiente em seus exercícios e em sua atenção.

Em determinado momento, durante a realização da atividade, perguntamos o que aconteceria com a energia potencial caso diminuíssemos a altura, tendo por base o solo. Essa pergunta foi respondida por vários alunos da seguinte forma: “A energia nesse ponto será zero." (Foco 2).

Os focos identificados nesta pesquisa, durante o desenvolvimento dessa atividade lúdica, foram os Focos 1, 2 e 3. Nos fragmentos anteriores, trouxemos uma exemplificação da presença dos Focos 2 e 3. Na sequência deste artigo, nos dedicamos à segunda etapa da análise dos dados, com a intenção de classificar as unidades de pesquisa de acordo com as fases do desenvolvimento do interesse (Foco 1) mais evidenciado por nós. Nos Quadros 3 e 4 inserimos excertos dos diálogos referentes às Fases 1 e 2 de Hidi e Renninger (2006) e destacamos que, nessa atividade pesquisada, não tivemos evidências das Fases 3 e 4, fato que se justifica pelas caracterizações expostas no Quadro 4, pelo fato de ser preciso mais contato com esses estudantes e pesquisá-los durante um período de tempo mais alongado, visto que, no nosso caso, foram somente dois dias de atividade.

Quadro 3: Fase 1 e alguns exemplos de manifestações.

\begin{tabular}{|l|l|}
\hline \multicolumn{2}{|c|}{ Fase 1: Interesse Situacional Acionado } \\
\hline Alunos & Unidades de pesquisa \\
\hline Aluno 2 & Por que a energia potencial é alta quando o Bob está na ponta da pista? \\
\hline Aluno 3 & Na pista 3, é como se fosse um negócio de revezamento... \\
\hline Aluno 4 & Nossa! Quando o Bob desce na pista, a energia cinética sobe. \\
\hline Aluno 1 & Nossa professora, aprender com esse joguinho é muito mais legal! \\
\hline Aluno 5 & Assim fica mais fácil de aprender, fazendo essas simulações... \\
\hline Aluno 6 & Professora, têm simulações de outras matérias também? \\
\hline
\end{tabular}

Fonte: Os autores.

O Interesse Situacional Acionado representa o despertar do estudante para aprender determinado conteúdo. É um estímulo inicial, que cria uma atmosfera favorável para a aprendizagem. Utilizamos os critérios apontados por Hidi e Renninger (2006) para categorizar os comentários dos 
estudantes nessa fase do desenvolvimento do interesse. Quando o Aluno 1 diz que aprender com o "joguinho" é muito mais legal, ele teve o interesse acionado, certamente por sua familiaridade com jogos e simulações. O mesmo pode ser percebido na fala do Aluno 5. O Aluno 6 demonstra ter seu interesse despertado não só pela atividade em si, indicando uma extensão desse interesse para outras disciplinas, percebendo que o uso de simulações pode ser profícuo para a aprendizagem em outras áreas do conhecimento.

No Quadro 4, trazemos exemplos de alocações para a Fase 2 do interesse.

Quadro 4: Fase 2 e alguns exemplos de manifestações.

\begin{tabular}{|l|l|}
\hline \multicolumn{2}{|c|}{ Fase 2: Interesse Situacional Mantido } \\
\hline Alunos & Unidades de pesquisa \\
\hline Aluno 5 & $\begin{array}{l}{[\ldots] \text { o legal é que a gente pode fazer as simulações em casa. Tô usando para revisar o conteúdo }} \\
\text { para a prova... }\end{array}$ \\
\hline Aluno 6 & $\begin{array}{l}\text { Agora eu tô usando as simulações para estudar outros conteúdos, de química, biologia. Gostei } \\
\text { muito! }\end{array}$ \\
\hline Aluno 4 & {$[\ldots]$ a gente tá fazendo a atividade mesmo sem valer nota... (risos) } \\
\hline Aluno 3 & Todas as aulas poderiam ser assim, fica mais fácil de aprender... \\
\hline
\end{tabular}

Fonte: Os autores.

O Interesse Situacional Mantido é quando aquele "despertar inicial” possui uma abrangência temporal maior, se estendendo para além do momento da aula, fato que pode ser observado na fala do Aluno 5 quando ele diz estar usando as simulações para estudar para a prova. Esse acontecimento assegura que seu interesse pela ferramenta e pelo conteúdo foi mantido. O Aluno 6 relata que usa as simulações para outras disciplinas, demonstrando que houve uma extrapolação do limite epistêmico proposto na realização da atividade, pois o estudante percebe o lúdico como uma possibilidade para aprendizagem em outros campos do saber.

Compreendemos que os relatos aqui exemplificados, assim com outros que não foram inseridos neste artigo, representam o Interesse Situacional Mantido, pois nos remetem a um estado de atenção e persistência durante um período extenso e/ou que ocorre novamente e persiste.

Ressaltamos que a atividade foi desenvolvida em 2 (dois) sábados, sendo facultativa a participação dos estudantes. Dos 25 alunos da turma, 17 se dispuseram a participar. Como já indicamos, embora no escopo teórico do trabalho sejam apresentadas quatro fases do desenvolvimento do interesse, o curto intervalo de tempo em que foi desenvolvida a atividade não nos permite mensurar as duas últimas fases.

\section{CONSIDERAÇÕES FINAIS}

A realização da atividade com os estudantes utilizando o software Phet nos mostra que o uso de jogos e atividades lúdicas é um caminho que cria elementos para o estabelecimento de uma atmosfera favorável à aprendizagem. Tal fato já é resultado de pesquisas nessa temática, como colocado na introdução deste artigo.

Percebemos que as pesquisas envolvendo o lúdico no ensino de ciências estão se direcionando para uma dimensão que vai além do simples relato do interesse dos alunos, preocupando-se com uma tentativa de mensuração de sua aprendizagem. Conforme relatamos de antemão, essa mensuração é algo complexo, pois a aprendizagem envolve múltiplos fatores. Entendemos que os Focos da Aprendizagem Científica (FAC) apresentam-se como um instrumento que possui grande potencial de análise dessa aprendizagem, pois permite verificar indícios de sua existência em várias dimensões. A identificação de três dos focos, como evidenciado na realização desta investigação, cujos resultados 
aqui apresentamos, leva-nos a inferir que algumas dimensões da aprendizagem foram atingidas na realização da atividade.

Com relação à segunda parte da análise dos dados, estritamente na dimensão do interesse Foco 1 - dialogamos e assumimos, para nossas interpretações dos dados, um referencial da psicologia cognitiva - as quatro fases do interesse - crendo que ele possa elucidar as compreensões relativas a essa dimensão da aprendizagem - o interesse.

\section{REFERÊNCIAS}

ARRUDA, S. M.; PASSOS, M.; PIZA, C.; FELIZ, R. O aprendizado científico no cotidiano. Ciência \& Educação, v. 19, n. 2, p. 481-498, 2013.

BROUGÈRE, G. Jogo e educação. 8. ed. Porto Alegre: Artmed, 2008.

CHATEAU, J. O jogo e a criança. São Paulo: Summus, 1987.

FENICHEL, M.; SCHWEINGRUBER, H. A. Surroundec by science: learning sicence in informal environments - based on the National Research Council report Learning science in informal environments: people, places and pursuits. Washington: Nacional Academies Press, 2010.

FLICK, U. Introdução à pesquisa qualitativa. Trad. de Joice Elias Costa. 3. ed. Porto Alegre: Artmed, 2009.

GARCEZ, E. S. C. Jogos e atividades lúdicas em ensino de Química: um estudo do estado da arte. Goiânia, 2014. 149fp. Dissertação (Mestrado em Educação em Ciências e Matemática) - Pró-Reitoria de Pesquisa e PósGraduação, Universidade Federal de Goiás, 2014.

GATTI, B. A construção da pesquisa em educação no Brasil. Brasília: Plano, 2002.

HIDI, S.; RENNINGER, K. A. The four-phase model of interest development. Educational Psychologist, , v. 41, n. 2, p. 111-142, 2006.

HUIZINGA, J. Homo Ludens: o jogo como elemento de cultura. São Paulo: Perspectiva, 2001.

MARTIN, G. F. S. Caracterização do interesse pela docência em estudantes participantes do PIBID em cursos de Ciências Naturais. Tese (Doutorado em Ensino de Ciências e Educação Matemática) - Universidade Estadual de Londrina, Centro de Ciências Exatas, Programa de Pós-Graduação em Ensino de Ciências e Educação Matemática, 2016.

MESSEDER, H.; MORADILLO, E. O lúdico no ensino de Química: considerações a partir da Psicologia HistóricoCultural. Química Nova na Escola, v. 38, n. 4, p. 360-368, 2016.

NACIONAL RESEARCH COUNCIL. How people learn: brain, mind, experience and school. Washington: Nacional Academies Press, 1999.

OLIVEIRA, A.; SOARES, M. Júri químico e a discussão de conceitos químicos. Química Nova na Escola, n. 21, p. 18-24, 2005.

RAMOS, E. M. F. Brinquedos e jogos no ensino de Física. 1990. Dissertação (Mestrado) - Instituto de Física, Universidade de São Paulo, 1990.

ROSA, S. Brincar, conhecer e ensinar. São Paulo: Cortez, 2002.

SOARES, M. H. F. B. Jogos para o ensino de Química: teoria, métodos e aplicações. Guarapari: Ex Libris, 2008.

SOARES, M. H. F.B. O lúdico em Química: jogos em ensino de Química. 2004. Tese (Doutorado) Departamento de Química, Universidade Federal de São Carlos, São Carlos, 2004.

Sérgio Silva Filgueira: Licenciado em Física pela UFG - 2004. Mestre em Educação em Ciências e Matemática pela UFG - 2009. Doutorando em Ensino de Ciências e Educação Matemática - UEL. Professor do Instituto Federal de Goiás - Campus Anápolis. E-mail: sfilgueira7@gmail.com

Ludimila Monteiro da Silva: Licenciada em Química pelo Instituto Federal de Goiás - Campus Anápolis (2015). E-mail: ludimila monteiro@hotmail.com 